\title{
EDUCAÇÃO FÍSICA E ATENÇÃO PRIMÁRIA À SAÚDE: APROPRIAÇÕES ACERCA DO APOIO MATRICIAL
}

\author{
PHYSICAL EDUCATION AND PRIMARY HEALTH CARE: UNDERSTANDINGS \\ ABOUT "MATRIX SUPPORT"
}

\section{EDUCACIÓN FISICA Y ATENCIÓN PRIMARIA A LA SALUD: APROPIACIONES ACERCA DEL APOYO MATRICIAL}

\section{Braulio Nogueira de Oliveira*, Felipe Wachs**}

\section{Palavras chave: Sistema Único de Saúde. \\ Atenção Primária à \\ Saúde. Estratégia \\ Saúde da Família. Educação Física e Treinamento.}

Resumo: A atenção primária à saúde se fortaleceu nas últimas duas décadas no Brasil. Recentemente, os Núcleos de Apoio à Saúde da Família permitiram que o leque de profissões transitando pela atenção primária aumentasse. Recomenda-se que essa inserção e trânsito estejam orientados pela lógica do Apoio Matricial. Este artigo analisa a apropriação dos profissionais de Educação Física acerca do Apoio Matricial. Trata-se de um estudo qualitativo, em que utilizamos grupo focal e observação participante com 11 profissionais de Educação Física da cidade de Sobral/CE. Os resultados sugerem seu entendimento como movimento de troca, de caráter técnico-pedagógico; 0 apoiador como corresponsável, em uma dimensão de Cogestão do Cuidado; bem como 0 apoio como uma tecnologia não engessada, mas como postura profissional. Conclui-se que os participantes da pesquisa compreendem o Apoio Matricial como um arranjo de corresponsabilidade entre especialistas e equipes de referência, que permite potencializar o cuidado usuário centrado.

Keywords: Unified Health System. Primary Health Care. Family Health Strategy. Physical Education and Training.
Abstract: Primary Health Care has strengthened in Brazil in recent decades. The Family Support Health Centers have caused an increase in the range of occupations that transit through Primary Health Care. It is recommended that this inclusion and transit be guided by the "Matrix Support" logic. This article analyzes the appropriation of "Matrix Support" by Physical Education professionals. This is a qualitative study that used a focus group and participant observation with 11 Physical Education professionals from the city of Sobral, state of Ceará. The results suggest its understanding as a technicalpedagogical movement of exchange; the supporter as co-responsible, in a dimension of Co-Management of Care; as well as support as a technology that is not frozen, but rather a professional stance. Research subjects were found to comprise "Matrix Support" as a coresponsibility arrangement between experts and reference teams, which allows enhancing patient-centered care.
Palabras clave: Sistema Único de Salud. Atención Primaria de Salud. Estrategia de Salud Familiar. Educación Física y Entrenamiento.
Resumen: La atención primaria a la salud se ha fortalecido en las dos últimas décadas en Brasil. Recientemente, los Núcleos de Apoyo a la Salud de la Familia han permitido que otras profesiones se insieran en la atención primaria. Se recomienda que este proceso sea guiado por la lógica del Apoyo Matricial. Este artículo analiza la apropiación por parte de los profesionales de Educación Física del conocimiento sobre el Apoyo Matricial. Se trata de un estudio cualitativo que utiliza grupo focal y observación participante con 11 profesionales de Educación Física de la ciudad de Sobral, Ceará. Los resultados sugieren su comprensión como movimiento de intercambio, con carácter técnico-pedagógico; quien apoya es visto como corresponsable, en una dimensión de Cogestión del Cuidado; así como el apoyo como una tecnología no rígida, sino más bien como una postura profesional. Se concluye que los profesionales de Educación Física que participaron en la investigación comprenden el apoyo matricial como un arreglo de corresponsabilidad entre especialistas y equipos de referencia, que permite potenciar el cuidado centrado en el usuario.
*Universidade Federal do Rio Grande do Sul. Porto Alegre, RS, Brasil. E-mail: brauliono08@hotmail.com

**Universidade Federal de Goiás. Goiânia, GO, Brasil. E-mail: felipewachs@gmail.com

Recebido em: 12-12-2016 Aprovado em: 13-12-2017

$\mathrm{DOl}$ http://dx.doi.org/10.22456/1982-8918.69965 (c) (1) (8) Licence 


\section{INTRODUÇÃO}

Atenção Primária à Saúde (APS), prevenção de doenças e promoção da saúde ganharam importância no cenário internacional com marcos como o Informe Lalonde (1974), a Declaração de Alma Ata (1978) e a Carta de Ottawa (1986). A compreensão de saúde se tornou mais complexa e, consequentemente, a gama de ações e a trama de relações em torno dela, mais amplas.

No contexto brasileiro, durante a década de 1990, são instituídos alguns programas que procuram materializar bandeiras do recém-criado Sistema Único de Saúde (SUS), tais como: universalidade, integralidade e equidade. Em 1991, foi criado o Programa de Agentes Comunitários em Saúde (PACS) e, em 1994, é instituído o Programa de Saúde da Família (PSF) (ÁVILA, 2011). O PSF passa a ser chamado de Estratégia Saúde da Família (ESF) alguns anos depois (ÁVILA, 2011) e torna-se mais complexo em termos de organização e de ações, em função, por exemplo, da criação dos Núcleos de Apoio à Saúde da Família (NASF) em 2008 (BRASIL, 2010) e das Academias da Saúde em 2011 (SKOWRONSKI; FRAGA, 2016).

Apesar de já existirem profissionais de Educação Física trabalhando em algumas experiências da APS anteriormente, sua inserção sistemática na ESF se materializa com a criação do NASF em 2008. 0 NASF, no entanto, propõe uma orientação para o trabalho, uma perspectiva de intervenção que é distinta do que seus profissionais estão habituados, rompendo com práticas historicamente constituídas e exigindo uma desterritorialização disciplinar. De acordo com o documento do Ministério da Saúde que apresenta diretrizes para o NASF, ele "[...] não se constitui porta de entrada do sistema para os usuários" (BRASIL, 2010, p. 7) e "[...] o atendimento direto e individualizado ocorrerá apenas em situações extremamente necessárias" (BRASIL, 2010, p.8), ou seja, o NASF não deve se caracterizar como um centro de especialidades. Conforme o próprio nome do "núcleo" sugere, a função de seus profissionais é justamente apoiar as equipes de Saúde da Família. Nesse sentido, o documento indica que "o correto entendimento da expressão 'apoio', que é central na proposta dos NASFs, remete à compreensão de uma tecnologia de gestão denominada Apoio Matricial, que se complementa com o processo de trabalho em 'equipes de referência"' (BRASIL, 2010, p.11).

Trata-se de uma tecnologia leve e leve-dura em saúde ${ }^{1}$ que pode ser conceituada como um apoio especializado às equipes de referência. A equipe de referência é aquela que mantém um acompanhamento longitudinal do usuário, enquanto que 0 apoiador matricial não tem necessariamente relação direta e cotidiana com o usuário. Em geral, os profissionais do NASF desenvolvem seu trabalho como apoiadores matriciais e as equipes de Saúde da Família assumem a função de equipes de referência. Assim, essa tecnologia tem uma dimensão assistencial, direcionada a qualificar o cuidado em saúde da população, e uma dimensão pedagógica, visto o processo formativo em que a equipe de referência é envolvida (CAMPOS, 1999).

Mesmo com orientações para o trabalho presentes nas "Diretrizes do NASF", verificase a dificuldade das equipes de elaborarem sua atuação sustentada no Apoio Matricial (FRAGELLI, 2013). Para os profissionais de Educação Física, é uma elaboração dobrada, pois não é apenas essa tecnologia que é novidade, mas a própria vinculação à APS ainda é.

1 Do ponto de vista das tecnologias em saúde, há três categorias: tecnologia dura, que envolve estruturas, recursos materiais, normas, protocolos; leve-dura, que trata de saberes estruturados; e leves, que são aquelas relacionais, que envolvem acolhimento, vínculo e autonomia (MERHY, 1997). A rigor, a noção de Apoio Matricial desenvolvida, aproxima-se mais fortemente as categorias de tecnologia leve e leve-dura. 
Assim, verificamos que nas publicações científicas mais recentes (2014-2016) que tratam da Educação Física na APS, em especial nos NASF, que essa temática aparece poucas vezes e de forma ainda incipiente (ALMEIDA; SANTOS; SOUZA, 2016; BOPSIN; KUHN; FERREIRA, 2015; FERREIRA et al. 2016; MARTINEZ;SILVA; SILVA, 2014; NEVES et al., 2015; PRADO; CARVALHO, 2016; RODRIGUES et al., 2015; SANTOS et al., 2015; SANTOS; SCHUH et al., 2015; VIEIRA, 2016). É possível que a marginalização do tema nas produções acadêmicas da área dificulte uma inserção mais harmônica da Educação Física na Estratégia Saúde da Família e resulte em perspectivas limitadas de intervenção.

Diante disso, o presente artigo analisa a apropriação da tecnologia Apoio Matricial por profissionais de Educação Física através de grupos focais e de observações participantes realizados na cidade de Sobral/CE. A cidade foi escolhida a partir da experiência de um dos autores com a Residência Multiprofissional em Saúde da Família desenvolvida no local e pelo modelo de atenção em saúde do município privilegiar tecnologias leves, entre elas o Apoio Matricial, embora ainda se enfrentem muitos desafios (QUINDERÉ, 2008; TÓFOLI, 2007; SOUZA, 2011).

\section{METODOLOGIA}

A trajetória de Sobral/CE em relação à valorização da APS e da formação de recursos humanos para o SUS - bem como o fomento à organização dos processos de trabalho fundamentados no Apoio Matricial - fez da cidade um local relevante para a investigação da temática, levando-nos a optar por uma metodologia qualitativa de pesquisa nesse contexto delimitado.

Em relação aos sujeitos participantes do processo de construção dos dados, optamos por direcionar o convite a profissionais de Educação Física que tivessem relevante aproximação com o objeto deste estudo (Apoio Matricial). Foram observados os seguintes critérios: ser profissional de Educação Física; atuar ou ter atuado no âmbito da assistência por, no mínimo, seis meses na ESF; atuar no âmbito de ensino, pesquisa, gestão e/ou assistência na perspectiva da ESF. Foram considerados com envolvimento de atuação no "Ensino" aqueles que integravam corpo docente de universidade, residências em saúde e afins; "Pesquisa" os que estavam envolvidos em pós-graduação, como alunos ou professores de mestrado e doutorado; "Assistência" os que compunham equipes de NASF, do sistema municipal de saúde e residência na função de assistência à saúde; e "Gestão" para os que exerciam função administrativa, como coordenação de Unidades Básicas de Saúde ou cargos na Secretaria de Saúde. Assim, a pesquisa envolveu 11 sujeitos que, em geral, apresentavam mais de um envolvimento:

Quadro 1 - Área de atuação dos interlocutores do estudo, Sobral, Ceará, 2014.

\begin{tabular}{|c|c|}
\hline Atuação & Sujeitos envolvidos \\
\hline Ensino & 4 \\
\hline Pesquisa & 3 \\
\hline Assistência & 8 \\
\hline Gestão & 2 \\
\hline
\end{tabular}

Fonte: autoria própria 
O processo de produção dos dados ocorreu entre novembro de 2013 e janeiro de 2014 e teve como técnicas o grupo focal e a observação participante. Essas técnicas foram escolhidas tendo como princípio, também, a intencionalidade de valorizar um processo de construção coletiva.

O grupo focal envolve um grupo de pessoas que tem características em comum (GATTI, 2005), fato esse que se consolida no presente estudo pela expertise teórico-prática dos sujeitos na ESF, além de serem todos profissionais de Educação Física. Procuramos seguir os pressupostos metodológicos descritos por Kind (2004), que sugere: quantidade de encontros a depender da saturação do tema; quantidade de participantes: que seja entre seis e 15; e a duração média entre 90 e 120 minutos. Além disso, o local deve proporcionar conforto, privacidade, sem interferências sonoras e ser de fácil acesso.

Todos os encontros do grupo focal contaram com um moderador e dois observadores. O moderador foi responsável por mediar as discussões, retomar o foco na temática em eventuais distanciamentos e potencializar a alternância das falas. Os observadores produziram um relatório a partir do comportamento dos participantes e das manifestações não apreendidas pelas falas, mas por meio de sinais e gestos, por exemplo.

Assim, foram realizados três encontros. No primeiro encontro, que teve a duração de 85 minutos e a participação de dez sujeitos, foi apresentada a pesquisa, com posterior leitura e assinatura do Termo de Consentimento Livre Esclarecido e iniciadas as discussões. As problematizações giraram em torno dos seguintes questionamentos: o que vocês entendem por Apoio Matricial? Quais ações vocês desenvolvem enquanto profissionais de Educação Física na perspectiva do Apoio Matricial na ESF? Quais ações vocês acham que deveriam acontecer em relação ao Apoio Matricial da Educação Física na ESF? Quais os principais desafios e dificuldades que vocês visualizam no que concerne ao desenvolvimento dessas ações?

No segundo encontro, com duração de 84 minutos e a participação de nove sujeitos, foi, inicialmente, realizado um resgate do encontro anterior pelos participantes e, na sequência, foi apresentado um novo questionamento: quais as competências necessárias para o profissional de Educação Física atuar como apoiador matricial na ESF? No final desse encontro, foi pactuado com os sujeitos um cronograma para a realização da observação participante.

A observação participante possibilita apreender elementos do cotidiano não identificados por meio da fala, estando o observador inserido na prática dos sujeitos envolvidos com intuito de realizar uma investigação científica (MINAYO, 2008). O diário de campo foi utilizado como ferramenta de registro e produção de dados da observação participante. Os dados registrados em diário de campo foram utilizados para confrontar informações presentes nas discussões do grupo focal com a rotina dos profissionais e, sobretudo, para construir, conduzir e sistematizar o segundo e o terceiro encontros do grupo focal.

O material empírico construído durante os dois primeiros encontros de grupo focal e os registros no diário de campo das observações participantes foram sistematizados em temáticas provisórias, as quais foram levadas para um terceiro momento com o grupo focal. Esse encontro teve duração de 70 minutos e contou com a participação de nove sujeitos. As informações empíricas foram problematizadas com os interlocutores em um momento construtivo e pedagógico. Os participantes tiveram autonomia para realizar quaisquer alterações 
que considerassem pertinentes nos registros prévios. As discussões, em geral, reafirmaram os achados. Foram modificados alguns termos/nomes, mas não houve dissenso quanto aos achados.

Como técnica de sistematização das informações, foi utilizada a Análise de Conteúdo do tipo Análise Temática, na perspectiva de Minayo (2008). Desse modo, foi realizada uma leitura flutuante e exaustiva de todo material empírico construído, em que foi feita uma interface entre as temáticas emergentes e o referencial teórico adotado, em especial dos postulados de Gastão Wagner de Sousa Campos. Ao aprofundarmos a análise desta temática no material produzido, destacaram-se três núcleos de sentido: dimensão pedagógica como movimento de troca; cogestão do cuidado e corresponsabilização do apoiador; e seu não engessamento institucional. Esses núcleos foram agrupados, procedendo à organização das informações no sentido de identificar convergências, divergências e complementaridades.

\section{DIMENSÃO PEDAGÓGICA COMO MOVIMENTO DE TROCA}

O primeiro núcleo de sentido referenda orientação já prevista nas premissas do Apoio Matricial; no entanto, dada a experiência dos sujeitos participantes da pesquisa com essa ferramenta, emergiram elementos ainda não previstos no referencial normativo, os quais constituíram, efetivamente, essa categoria.

Ao abordarem o rearranjo organizacional proposto com essa tecnologia, os sujeitos evidenciam que o suporte à equipe é permeado por um significativo caráter técnico e pedagógico. De acordo com o Sujeito 4 (grupo focal 1), o Apoio Matricial "[...] é uma tecnologia em saúde, que é para produzir um apoio técnico-pedagógico, a partir do trabalho, visando à necessidade de saúde tanto do usuário quanto às necessidades da equipe para organização do serviço". Esse pensamento é sinérgico ao conceito proposto por Campos e Domitti (2007), no que se refere a contemplar a demanda dos usuários e das equipes de saúde. Os sujeitos da pesquisa enfatizam essa potência na tecnologia, tendo em vista que consideram esse processo como dialógico, de "troca", como observamos no discurso do Sujeito 1 e do Sujeito 3:

\footnotetext{
Assim, eu percebo que o matriciamento é um espaço de troca, de construção coletiva, muitas vezes se trabalha a ideia de que é um profissional, especialista, que vai lá e dá um suporte à equipe. A gente percebe que no ambiente de matriciamento há um movimento de troca, aquele profissional que muitas vezes está ali para receber o matriciador, ele também fornece Apoio [...] (Sujeito 1, grupo focal 1).

[...] eu entendo pelo matriciamento, tem esse caráter pedagógico, então sempre tem que ter o matriciador, e que esse apoio tem que vir de ambas as partes [...] (Sujeito 3, grupo focal 1).
}

Durante os relatos, os observadores do grupo focal registraram sinais de aprovação dos demais sujeitos, o que sugere certa representatividade por parte dos demais. O Sujeito 1 ressalta o processo dialógico que permite que a discussão das condições de saúde/doença e a construção do plano de cuidado ocorram de forma compartilhada entre a equipe de referência e o apoiador matricial, no caso, o profissional de Educação Física. Ou seja, ao mesmo tempo em que o especialista contribui com seus saberes, a equipe de referência possui saberes alheios ao apoiador. Assim, o Apoio Matricial não instaura uma relação de quem sabe instruindo quem não sabe. Para que essa tecnologia seja operacionalizada de forma potente, o apoiador precisa 
aprender com a equipe de referência sobre o contexto da APS, sobre a comunidade atendida e sobre a singularidade do usuário. Aposta-se que, nesse encontro de saberes e de profissionais, as estratégias de cuidado serão mais consistentes, efetivas e resolutivas.

Diante do arranjo organizacional proposto, o papel da equipe de referência não se restringe à condução do caso e ao acompanhamento longitudinal por possuir maior vinculação com os usuários. No processo dialógico, a equipe de referência não se limita a ser "receptora do suporte" ou passiva na dimensão formativa da tecnologia. Podemos dizer que o Apoio Matricial constitui uma via de educação permanente com duas mãos, pois, ao mesmo tempo em que a equipe de APS estará mais bem preparada para lidar com casos ligados àquela especialidade, também o apoiador estará mais bem preparado para desempenhar seu papel em situações semelhantes de apoio. Nesse sentido, o Sujeito 2 (grupo focal 1) argumenta: "Um elemento importante no Apoio Matricial é a discussão do caso, se não, não há troca; e é necessariamente para rever os casos e aí tirar as dúvidas que há em relação àquele caso".

Com isso, o apoiador matricial pode ser compreendido também como profissional aprendente (OLIVEIRA; WACHS, 2015), e a qualidade de sua atuação profissional estará diretamente associada a essa postura/condição. Essa discussão promove reflexões em se tratando do desafio da produção da autointerrogação de si mesmo no agir produtor do cuidado, ao se colocar ético-politicamente em discussão no plano individual e coletivo do trabalho (MERHY, 2005). Alertamos, portanto, para a pertinência da busca incessante da consolidação da pedagogia da implicação para posterior mudança na forma de lidar com a saúde (MERHY, 2005). Tal postura, porém, não implica uma desresponsabilização por parte da gestão, sobretudo pela potência do acolhimento pedagógico aos profissionais do NASF, que se constitui como um dos principais aspectos para melhor desempenho pelos profissionais de Educação Física nas atividades de Apoio Matricial (SANTOS et al., 2017).

Assim, podemos destacar a importância que os participantes da pesquisa, através de suas falas, atribuem ao movimento de troca entre equipe de referência e apoiador matricial. Compreendemos, assim, que a dimensão pedagógica da tecnologia ocorre em duas vias, uma vez que é importante para um profissional de Educação Física, ao apoiar uma equipe de Saúde da Família, por exemplo, entender os aspectos socioculturais e sanitários da comunidade, sobretudo no que tange à cultura corporal de movimento. A disposição para essa postura contribuirá para com a construção de estratégias mais consistentes junto às comunidades e para a promoção de práticas constituídas de sentido para os indivíduos que não apenas evitar ou tratar determinada(s) doença(s).

\section{COGESTÃO DO CUIDADO E A CORRESPONSABILIZAÇÃO DO APOIADOR}

Embora no Apoio Matricial se busque uma qualificação das equipes de referência e 0 apoiador possa nem ter contato direto com o usuário, sua responsabilidade pelo caso não é isenta, implicando uma dimensão assistencial do apoio. Ele é corresponsável pelo acompanhamento do cuidado, diferente de propostas em que a centralidade está apenas na equipe de referência, ou no usuário - cerne do cuidado. Nesse sentido, aplica-se a cogestão do cuidado, a partir do entendimento de que todos os atores envolvidos possuem implicação nesse processo, desde que resguardada a incumbência da equipe de referência de coordenar 0 cuidado. Essa dimensão se manifesta na argumentação dos profissionais de Educação Física. 
O Apoio Matricial é um apoio, mas não é qualquer apoio, esse apoio, ele vai exigir uma dimensão de cogestão do cuidado em saúde, então, minha compreensão de apoio vai demandar que a equipe compreenda o que é cogestão do cuidado, envolvendo os profissionais, envolvendo o usuário, e vai remeter a um conteúdo que é a questão do Paideia que o Gastão tanto coloca, que é as relações de poder; não tem nenhum que sabe mais, e todos são capazes de aprender; tem a dimensão propriamente terapêutica do processo de trabalho, então a dimensão Paideia do Apoio Matricial traz a cogestão do cuidado e vai demandar o saber escutar, o saber falar, acho que é por aí (Sujeito 4, grupo focal 1).

Identificamos na fala do Sujeito 4 algumas premissas sobre cogestão do cuidado que apresentam aproximações ao método Paideia (CUNHA; CAMPOS, 2010). Nesse caso, destacamos, principalmente: as relações de poder; 0 empoderamento dos diferentes profissionais envolvidos; a autonomia dos usuários de saúde; 0 saber escutar e o saber falar; além da questão terapêutica e/ou de promoção de saúde que contempla o caráter técnico assistencial do Apoio Matricial.

O método Paideia atrela uma dimensão crítica e uma dimensão propositiva. A crítica se destina a uma análise reflexiva do mundo do trabalho e das instituições contemporâneas. Já a dimensão propositiva remete a um método de fato, de apoio e cogestão (CUNHA, CAMPOS, 2010). Nesse sentido, evidenciamos um compromisso com a democracia institucional, com a valorização da participação social nos diversos espaços. Ambas as dimensões incidem no Apoio Matricial, visto que envolve uma reorganização dos processos de trabalho e vai de encontro à lógica produtivista. Desse modo, na perspectiva da tecnologia em questão, reduz-se o foco em quantidade de atendimentos em detrimento da qualidade desses atendimentos, que passam a ter um papel formativo mais evidente.

Essa reorganização dos serviços remete a pensar como 0 trabalho do profissional de Educação Física é percebido pelos demais profissionais do serviço, diante do caráter interprofissional da proposta. Nesse sentido, Pedrosa e Leal (2012) identificaram que profissionais de Medicina e Enfermagem de Porto Velho têm posicionamento favorável à inserção da categoria nas ações da ESF. Xavier e Espirito-Santo (2013), ao entrevistar ACS e profissionais de Enfermagem da ESF no Rio de Janeiro, evidenciaram o otimismo e confiança no trabalho da equipe, representando a categoria como responsável prioritariamente pela implantação de programas de exercícios físicos. 0 estudo de Lima, Oliveira e Oliveira (2015) apresentou resultados semelhantes em Limoeiro do Norte, onde os membros das equipes de Saúde da Família se dizem contemplados com o apoio realizado pela categoria. Essa articulação entre as categorias é relevante na medida em que há uma expectativa de que todos os trabalhadores em saúde sejam corresponsáveis pelos casos, com agenda por vezes compartilhada.

Outro elemento importante evidenciado na observação participante junto aos profissionais colaboradores da pesquisa - porém não explícito em suas discussões durante os grupos focais - é a amplitude do caráter participativo da cogestão, em que também os usuários se colocam como coparticipantes da construção e da gestão de seus projetos terapêuticos. Nessa perspectiva, a elaboração de estratégias assistenciais durante 0 apoio pauta-se pela construção de possíveis caminhos, tendo atuação não direcionada a práticas verticalizadas e medicalizantes de promover saúde. Ou seja, o Apoio Matricial da Educação Física não consiste apenas em transmitir uma mensagem dura e pormenorizada, a ser replicada pela equipe de 
referência sobre os exercícios e/ou recomendações padronizadas de atividade física que determinada pessoa ou comunidade deva desenvolver. 0 apoiador participa da construção das estratégias, mas também tem responsabilidade por acompanhar sua efetivação, avaliar seu desenvolvimento e seus resultados. Se os exercícios orientados a determinado indivíduo ou as estratégias de promoção de atividade física em uma determinada comunidade estão com resultados aquém do esperado, a responsabilidade é compartilhada entre apoiador, equipe de referência e usuários. Diante desse quadro, o apoiador pode propor e participar de avaliações mais detalhadas, de atendimentos compartilhados ou participar ativamente da organização de enlaces intersetoriais que permitam contemplar as necessidades assistenciais da população. Assim, a atuação do profissional de Educação Física como apoiador matricial requer corresponsabilização pelo cuidado, apesar da condução do caso continuar a ser de incumbência das equipes de referência, em um processo usuário-centrado.

\section{NÃO ENGESSAMENTO INSTITUCIONAL DO APOIO MATRICIAL}

A terceira categoria que estruturamos sobre o entendimento dos sujeitos acerca do Apoio Matricial é o seu caráter não rígido. Nessa concepção, a abrangência da tecnologia em exercício não se restringe aos espaços formais, aqui ditos institucionalizados. Compreendemos como formais, ou institucionalizados, aqueles espaços que organicamente estão inseridos na organização dos serviços de saúde, no sentido de terem cronograma e procedimentos predefinidos. Não se trata de questionar a regularidade ou o agendamento de reuniões que propiciem sua operacionalização, mas de convocar algumas reflexões: qual a abrangência dessa tecnologia? Quem é apoiado ou pode ser apoiado? Em que momento o apoio está ocorrendo?

Nessa categoria, existem algumas divergências e peculiaridades de posição entre os participantes dos grupos focais. Em uma dessas nuances de posição, cobra-se uma organicidade maior do Apoio Matricial nos processos de trabalho em saúde, no sentido de serem "institucionalizadas", conforme podemos observar no discurso do Sujeito 4:

\footnotetext{
Outro desafio que eu vejo é assim, eu concordo que a dimensão do Apoio Matricial acontece sem a dimensão institucional, nos corredores e entrelinhas, mas me parece que precisa de uma certa forma, uma reorganização, da ESF, no sentido de compreender e passar a abrir mais para garantir até a institucionalização do Apoio Matricial, porque é importante, porque fica muito no clandestino, acontece aqui, acontece ali, mas de fato a organização, a gente não encontra isso de maneira orgânica, vamos dizer assim (Sujeito 4, grupo focal 1).
}

Durante a observação participante, pudemos verificar aquilo que foi sinalizado pelo Sujeito 4 e concordar que, no contexto de Sobral/CE, o espaço de Apoio Matricial que se encontra mais consolidado é aquele ligado à saúde mental e institucionalizado através da Rede de Atenção Psicossocial. Nessa rede, são promovidos encontros sistemáticos nos quais são discutidos casos encaminhados pelas Equipes de Saúde da Família. Esses encontros podem envolver outros atores, como os profissionais do NASF e da residência multiprofissional. Pelo tempo requerido em função da dimensão pedagógica envolvida, durante um turno de trabalho são discutidos aproximadamente quatro casos. Com isso, reformulamos o questionamento: os espaços aqui denominados institucionalizados são suficientes para contemplar as demandas que envolvem essa tecnologia? 
Como uma das múltiplas facetas que esse debate pode engendrar, o Sujeito 1 indica que sua operacionalização pode ocorrer no cotidiano, como uma ferramenta não rígida, portanto, não institucionalizada.

Muitas vezes, quando eu vou realizar visita com a psicóloga da minha equipe, a gente troca experiência sobre aquele caso, a gente tá fazendo o Apoio Matricial. Não necessariamente é um espaço que, sei lá, o Apoio Matricial da Saúde Mental, não, mas a partir do momento em que eu troco experiência com a minha agente de saúde, ou com a minha gerente, ou com a enfermeira, a gente está fazendo Apoio Matricial (Sujeito 1, grupo focal 1).

O referencial teórico da análise deste estudo não se aprofunda nessa dimensão não institucional, mas buscamos realizar uma interface entre a literatura acerca dessa tecnologia e a narrativa dos sujeitos. Campos e Domitti (2007), por exemplo, tratam essa tecnologia como eminentemente relacionada à construção de um projeto terapêutico integrado, sendo desenvolvidos três direcionamentos fundamentais: (i) atendimentos e intervenções conjuntas; (ii) em situações que exijam atenção específica ao núcleo de saber do apoiador, isso ocorre nos casos que carecem de uma atuação individual do apoiador, desde que este mantenha contato com a Equipe de Referência; e (iii) o apoio restrito apenas à troca de conhecimento e de orientação entre equipe e orientador, na perspectiva do diálogo (CAMPOS; DOMITTI, 2007).

Compreendemos que o Apoio Matricial é proposto como uma transgressão à lógica hegemônica do encaminhamento na gestão do cuidado. A partir da sistematização de experiências positivas que propiciaram um rearranjo dessa gestão, ele se constituiu, ganhou contornos e um nome. Com isso, pode então ser apresentado como orientador dos processos de trabalho do NASF, por exemplo. O processo de institucionalizar um movimento de transgressão ao que era considerado um problema traz benefícios à organização da gestão, mas também engessa possibilidades e diminui a potência criativa do cuidado vivo em ato que o movimento continha. Ao estabelecer orientações eminentemente rígidas de como essa prática deve ser, sobra menos espaço para aquilo que o apoio poderia ser, menos margem para sua potência instituinte. Por outro lado, o estabelecimento de alguns contornos para a ferramenta permite que ela receba investimentos, tempo dentro dos processos de trabalho nos serviços, espaço na formação profissional, e possibilita que ela seja avaliada e valorizada na organização e na gestão do sistema de saúde.

As discussões em torno de certo caráter informal geraram reflexões inclusive sobre a possibilidade de nominar como Apoio Matricial ações que foram desenvolvidas por eles antes da formação do conceito, e que envolviam grupos de práticas corporais:

Na verdade, eu vou contar uma história que a gente tem como acúmulo de vida, que, na verdade, se a gente for fazer um resgate no campo da Educação Física, especificamente no município de Sobral, no Saúde da Família, digamos que existia uma dimensão de Apoio Matricial, mas a gente não tinha essa consciência teórica. Quando você vai ver na literatura ou vai ver relatos de alguns profissionais que já passaram pelo sistema, nós conseguimos organizar vários grupos de práticas corporais de caminhada, em que dois profissionais conseguiram articular vários grupos com o apoio da gestão e do Agente Comunitário de Saúde (ACS); me parece que aí já se começava a se desenhar uma dimensão de Apoio Matricial, dentro do campo, a partir do núcleo Educação Física dentro da ESF, onde tínhamos um grupo de profissionais ACS e tinham dois ou três profissionais [de Educação Física], para dar esse apoio e disseminar essa prática. Talvez seja por aí que comece um fazer Apoio Matricial dentro do núcleo da Educação Física (Sujeito 4, grupo focal 1). 
O relato aponta para uma perspectiva de intervenção voltada para a criação ou manutenção de grupos de práticas corporais - o Apoio Matricial de profissionais de Educação Física, direcionado a grupos cuidados por ACS. Trata-se de uma prática não evidenciada em estudos que investem na inserção da categoria no NASF (ALMEIDA; SANTOS; SOUZA, 2016; BOPSIN; KUHN; FERREIRA, 2015; FERREIRA et al., 2016; RODRIGUES et al., 2015; SCHUH et al., 2015; VIEIRA, 2016), mas fortemente relatada pelos sujeitos. A atuação do profissional de Educação Física como apoiador de seu núcleo de saber práticas corporais/atividade física estabelece franco conflito com discursos corporativistas da área. É recorrente que o discurso corporativista enuncie que o exercício físico deva ser sempre prescrito por um profissional de Educação Física, ou pior, que deva ser realizado, necessariamente, na presença e sob supervisão desse profissional. Para esse discurso, a autonomia dos sujeitos representa atrofia do mercado de trabalho e a estruturação de um Apoio Matricial que dê sustentação para que um ACS promova práticas corporais/atividade física e saúde é inconcebível. Por outro lado, os sujeitos argumentam que nossa função, para o trabalho com essa tecnologia, vai além do movimento humano. Para o Sujeito 5:

[...] a prática corporal, ela vem no desenrolar de outros processos [...] até onde nós estamos, fugindo da nossa função, saindo um pouco da nossa caixinha, de prática corporal. [...] Será que estamos saindo da caixinha da gente, de categoria, e entrando realmente na cogestão do processo? Aí, sim, a gente vai começar a fazer Apoio Matricial, que é uma cogestão, então a gente tem que começar, acho que uma das coisas que a gente precisa estar avançando, poderia ser feito cada vez mais, é sair desse quadrado que a gente se coloca, e a partir daí a gente começar a entender os processos, a ter mais atendimento compartilhado, que também é Apoio Matricial (Sujeito 5, grupo focal 1).

Apesar das divergências manifestas pelos sujeitos no que tange à presente categoria de análise, a concepção emergente das manifestações apresenta defesa do não engessamento da tecnologia, sendo preciso avançar para um caráter de postura profissional - assistencial e pedagógica. A atuação do apoiador não precisa se restringir aos espaços formais, e pode agregar funções como a articulação intersetorial na busca de melhor atender as demandas das comunidades cujas equipes de referência apoiam. Nesse sentido, restringir demais normativamente a quem o Apoio Matricial deve se voltar, quando deve ocorrer e as formas como ocorre tende a diminuir a potência da tecnologia. A existência de processos não institucionalizados, no entanto, não exime os processos formais, que, por sua vez, contribuirão para consolidação da tecnologia.

\section{CONSIDERAÇÕES FINAIS}

O Apoio Matricial ainda é incompreendido e encontra resistência por alguns profissionais, mesmo daqueles vinculados a serviços como o NASF, que possui tal tecnologia como um orientador dos processos de trabalho. No contexto da atuação do profissional de Educação Física, ainda é mais fácil e cômodo se limitar a estruturar e acompanhar semanalmente um grupo de usuários para realização de determinada prática corporal. Certamente que coordenar grupos nas comunidades cujas equipes estão ligadas ao seu NASF é uma forma de o profissional prestar apoio às equipes no sentido de ampliar as práticas de saúde ofertadas às comunidades. No entanto, é importante diferenciar esse tipo de apoio da proposta do Apoio Matricial. 
Compreendemos o Apoio Matricial como tecnologia que tem, em sua origem, o intento de primar por um trabalho em saúde que respeite a integralidade do sujeito e a possibilidade de uma maior integração entre profissionais e seus saberes, ao passo que "transgride" a hegemonia da lógica organizacional do encaminhamento e traça estratégias de cuidado sustentadas na corresponsabilização e centradas no usuário.

A análise, em nossa pesquisa, do entendimento dos sujeitos que operam com essa tecnologia, a partir de sua vivência no campo da Educação Física, envolveu três núcleos de sentido. $O$ primeiro trata da dimensão pedagógica presente em sua operacionalização, na qual a "troca" de experiências/saberes foi valorizada. Nossos colaboradores defenderam que a expertise da Educação Física sobre as práticas corporais/atividade física deve dialogar com os saberes socioculturais e sanitários da equipe de referência acerca das comunidades para que as estratégias construídas sejam mais efetivas e resolutivas. $O$ segundo núcleo de sentido demarca a valorização da cogestão do cuidado e da corresponsabilização do apoiador. Mesmo que a equipe de referência ainda seja apresentada como a responsável pelo acompanhamento longitudinal, a responsabilidade pelos casos e pelas estratégias, bem como a participação em eventuais avaliações, é apresentada como corresponsabilidade dos apoiadores matriciais. Para que isso se operacionalize, é necessário romper com práticas verticais e medicalizantes, abrindo espaço para relações mais dialógicas.

O terceiro núcleo trata do destaque dado à necessidade de não engessamento institucional da tecnologia, que sugere a noção de um conceito-postura, sem demandar, necessariamente, horário, data e local predefinido. Isso se desdobra em duas vias: não engessar a relação entre apoiador e equipe de referência, criando excessivas regras de como 0 apoio deve acontecer; e compreender que o apoio não precisa se restringir ao interior institucional do setor saúde, mas pode se desdobrar de forma intersetorial ou informal no território. Se o intuito é investir na promoção de saúde da população adstrita, apoiar os dispositivos comunitários que potencializam a promoção de práticas corporais pode ser uma boa estratégia.

Vale ressaltar que o Apoio Matricial envolve uma ampliação do escopo das ações de determinado núcleo/categoria profissional, a partir da apropriação desse saber. Investe de tal maneira na autonomia das equipes de referência que, ao surgirem casos semelhantes, espera-se que a equipe saiba lidar com essa demanda. Isso contrasta fortemente com 0 pensamento corporativista de que o saber referente ao núcleo de determinada categoria - no caso da Educação Física, as atividades física/práticas corporais - é propriedade apenas do exercício profissional da categoria. Assim, destacamos que há resistência no fomento dessas estratégias, embora não encontrado no cenário desse estudo. Sobretudo, esperamos que 0 Apoio Matricial se efetive como uma possibilidade dos profissionais de saúde de investirem na promoção de saúde da população do(s) território(s) sob sua corresponsabilidade.

\section{REFERÊNCIAS}

ALMEIDA, Débora Alves; SANTOS, Tâmara Santana dos; SOUZA, Nubia Josania de Lira. A importância da inserção do profissional de educação física no núcleo de apoio à saúde da família. Caderno de Graduação-Ciências Biológicas e da Saúde-UNIT, v. 3, n. 2, p. 125-144, jan./jun. 2016. 
ÁVILA, Maria Marlene Marques. Origem e evolução do programa de Agentes Comunitários de Saúde no Ceará. Revista Brasileira em Promoção da Saúde, v. 24, n. 2, p. 159-168, abr./jun. 2011.

BOPSIN, Andressa Pires; KUHN, Giovanni; FERREIRA, Tiago. A inserção da Educação Física no núcleo de apoio à saúde da família-NASF-no município de Porto Alegre. Revista Didática Sistêmica, v. 16, n. 1, p. 430-432, jan./jun. 2015.

BRASIL. Ministério da Saúde. Secretaria de Atenção à Saúde. Departamento de Atenção Básica. Diretrizes do NASF: Núcleo de Apoio a Saúde da Família Brasília, 2010.

CAMPOS, Gastão Wagner de Sousa; DOMITTI, Ana Carla. Apoio matricial e equipe de referência: uma metodologia para gestão do trabalho interdisciplinar em saúde. Cadernos de Saúde Pública, v. 23, n. 2, p. 399-407, fev. 2007.

CAMPOS, Gastão Wagner de Sousa. Equipes de referência e apoio especializado matricial: um ensaio sobre a reorganização do trabalho em saúde. Ciência e Saúde Coletiva, v. 4, n. 2, p. 393-403, jul./dez. 1999.

CUNHA, Gustavo Tenório; CAMPOS, Gastão Wagner de Sousa. Método paidéia para co-gestão de coletivos organizados. Para o trabalho. Revista Org \& Demo, v.11, n.1, p. 31-46, jan./jun. 2010.

FERREIRA, Talitha et al. A inserção do Profissional de Educação Física nos Núcleos de Apoio a Saúde da Família: visão dos profissionais. Revista Brasileira de Atividade Física \& Saúde, v. 21, n. 3, p. 228-236, maio/jun. 2016.

FRAGELLI, Thaís Branquinho Oliveira. Análise das competências profissionais no núcleo de apoio à saúde da família. 2013. 176 f. Tese (Doutorado em Ciências da Saúde) - Programa de Pós-Graduação em Ciências da Saúde, Brasília, 2013.

GATTI, Bernardete Angelina. Grupo focal na pesquisa em ciências sociais e humanas. Brasília: Líber Livro, 2005.

KIND, Luciana. Notas para o trabalho com a técnica de grupos focais. Psicologia em Revista, v.10, n.15, p.124-136, jun. 2004.

LIMA, Lucídio José dos Reis; OLIVEIRA, Braulio Nogueira de; OLIVEIRA, Bergson Nogueira de. Representações sociais sobre o trabalho do profissional de educação física na atenção primária à saúde pelas equipes de saúde da família. Educação Física em Revista, v. 9, n. 2, p. 12-22, abr./jun. 2015.

MARTINEZ, Jéssica Félix Nicácio. SILVA, Ana Márcia. SILVA, Maria Sebastiana. As diretrizes do NASF e a presença do profissional de Educação Física. Motrivivência, v.26, n.42, p.222237, jun. 2014.

MERHY, Emerson Elias. Em busca do tempo perdido: a micropolítica do trabalho vivo em saúde. In: MERHY, Emerson Elias; ONOCKO, Rosana. Praxis en salud: un desafío para lo público. São Paulo: Hucitec, 1997. p. 71-112.

MINAYO, Maria Cecília de Souza. O desafio do conhecimento: pesquisa qualitativa em saúde. 11. ed. São Paulo: HUCITEC, 2008.

NEVES, Ricardo Lira de Rezende et al. Educação física na saúde pública: revisão sistemática. Revista Brasileira de Ciência e Movimento, v. 23, n. 2, p. 163-177, abr.jun.2015. 
OLIVEIRA, Braulio Nogueira. WACHS, Felipe. Educação Física e a Atenção Primária à Saúde: 0 apoiador matricial como profissional aprendente. In: CONGRESSO BRASILEIRO DE CIÊNCIAS DO ESPORTE, 19. Anais... Vitória, 2015. Disponível em: <http://congressos.cbce.org.br/index. php/conbrace2015/6conice/paper/view/7761>. Acesso em: 25 nov. 2016.

PRADO, Alessandro Rovigatti do; CARVALHO, Yara Maria de. Formação em Educação Física: experiências de integração ensino-serviço na atenção básica em saúde. Movimento v. 22, n. 2 , p. 635-646, abr./jun. 2016.

QUINDERÉ, Paulo Henrique Dias. Atenção à saúde mental no município de Sobral-CE: interações entre os níveis de complexidade, composição das práticas e serviços. 2008. $104 \mathrm{f}$. Dissertação (Mestrado em Saúde Pública) - Universidade Estadual do Ceará, Fortaleza, 2008.

RODRIGUES, José et al. Perfil e atuação do Profissional de Educação Física nos Núcleos de Apoio à Saúde da Família na região metropolitana de João Pessoa-PB. Revista Brasileira de Atividade Física \& Saúde, v. 20, n. 4, p. 352-365, jul./ago. 2015.

SANTOS, Sueyla Ferreira da Silva dos et al. Apoio Matricial e a atuação do Profissional de Educação Física do Núcleo de Apoio à Saúde da Família. Revista Brasileira de Atividade Física \& Saúde, v. 22, n. 1, p. 54-65, jan./fev. 2017.

SANTOS, Sueyla Ferreira da Silva dos et al. The work of physical education professionals in Family Health Support Centers (NASF): a national survey. Revista Brasileira de Cineantropometria e Desempenho Humano, v. 17, n. 6, p. 693-703, nov./dez. 2015.

SCHUH, Laísa Xavier et al. A inserção do profissional de educação física nas equipes multiprofissionais da estratégia saúde da família. Saúde (Santa Maria), v. 41, n. 1, p. 29-36, jan./jul. 2015.

SKOWRONSKI, Marcelo; FRAGA, Alex Branco. Academia da saúde e os diferentes saberes para atuação do profissional de educação física. In: WACHS, Felipe; ALMEIDA, Ueberson Ribeiro; BRANDÃO, Fabiana F. de Freitas. Educação Física e Saúde Coletiva: Cenários, experiências e artefatos culturais. Porto Alegre: Rede UNIDA, 2016. p. 223-242.

SOUZA, Maria Lidiany Tributino de. Apoio matricial em saúde mental: uma proposta de educação permanente em saúde? Sanare, v.10, n. 2, p. 28-33, jul./dez. 2011.

TÓFOLI, Luís Fernando, FORTES, Sandra. Apoio matricial de saúde mental na atenção primária no município de Sobral-CE: o relato de experiência. Sanare, v. 6, n. 2, p. 32-42, jul./dez. 2007.

VIEIRA, Ewerton Leonardo da Silva. Investigando a atuação dos profissionais de educação física das equipes do núcleo de apoio à saúde da família. 2016. 80f. Trabalho de conclusão de curso (Bacharelado em Educação Física) - Universidade Federal do Rio Grande do Norte, Natal, 2016.

XAVIER, Patrícia Pinto; ESPÍRITO-SANTO, Giannina do. Representações sociais do profissional de educação física pela equipe de estratégia saúde da família. Corpus et Scientia, v. 9, n. 2, p. 83-98, jul./dez. 2014. 
